\title{
АКТУАЛЬНЫЕ ВОПРОСЫ ИНФОРМАЦИОННОЙ БЕЗОПАСНОСТИ РАДИОСВЯЗИ МОРСКОГО И РЕЧНОГО ТРАНСПОРТА
}

\section{CURRENT ISSUES OF INFORMATION SECURITY OF RADIO COMMUNICATIONS OF SEA AND RIVER TRANSPORT}

V. Korotkov

A. Melnikov

Summary. Ensuring safe navigation in terms of information is one of the most urgent tasks of the modern state. One of the components of information security at sea is an information radio communication system. The main purpose of this work is to study topical issues related to ensuring information security of radio communications at sea. The author works through the use of statistical data and information, as well as empirical and theoretical research methods. For the purpose of more complete disclosure of the topic and obtaining reliable data, the author uses publications and materials from domestic and foreign sources.

Keywords: information security, river transport, secure radio communication, sea, system.

\author{
Коротков Виталий Валерьевич \\ Дочент, ФГБОУ ВО ГУМРФ имени адмирала \\ С.О. Макарова \\ Г. Санкт-Петербург \\ 9738132@mail.ru \\ Мельников Александр Валерьевич \\ ФГБОУ ВО ГУМРФ имени адмирала С.О. Макарова \\ Г. Санкт-Петербург
}

Аннотация. Обеспечение безопасного в информационном плане мореплавания является одной из самых актуальных задач современного государства. Одной из компонент информационной безопасности на море является система информационной радиосвязи. Основной целью данной работы является изучение актуальных вопросов, касающихся обеспечения информационной безопасности радиосвязи на море. Автором производится работа посредством применения статистических данных и информации, а также эмпирических и теоретических методов исследования. С целью более полного раскрытия темы и получения достоверных данных автором используются публикации и материалы отечественных и зарубежных источников.

Ключевые слова: информационная безопасность, речной транспорт, безопасная радиосвязь, море, система.

Системы радиосвязи с морскими подвижными объектами (МПО) - это множество средств, в свою очередь, удовлетворяющих потребности в связи МПО, а также эксплуатирующих их людей. Морскими подвижными объектами выступает любой транспорт на море, будь то плавучие буровые установки, какие-либо платформы, судна и иные объекты, выполняющие ряд поставленных задач, находящиеся в зоне морей и океанов.

На рис. 1 определены основные задачи радиосвязи на море:

Анализируя основные требования к радиосвязи с аспекта информационной безопасности, отметим, что ключевым требованием является поддержание надежной двусторонней связи судов с береговыми радиоцентрами и иными судами [3].

Каждая система радиосвязи включает пространственно-временные, технические и технологические характеристики. Информационная безопасность является одним из комплексных показателей системы радиосвязи, ключевые показатели которой формируются 


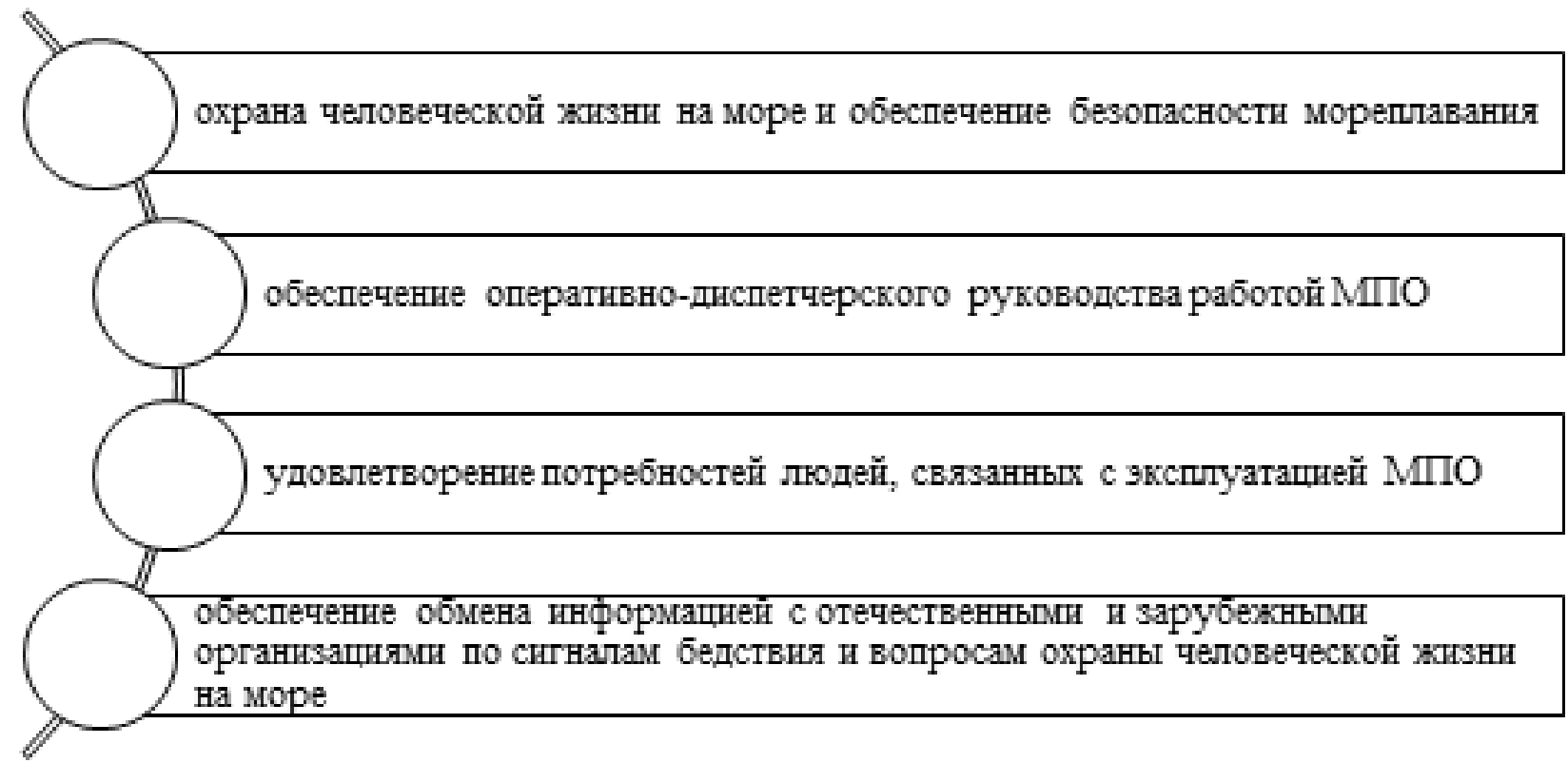

Рис. 1. Основные задачи радиосвязи на море

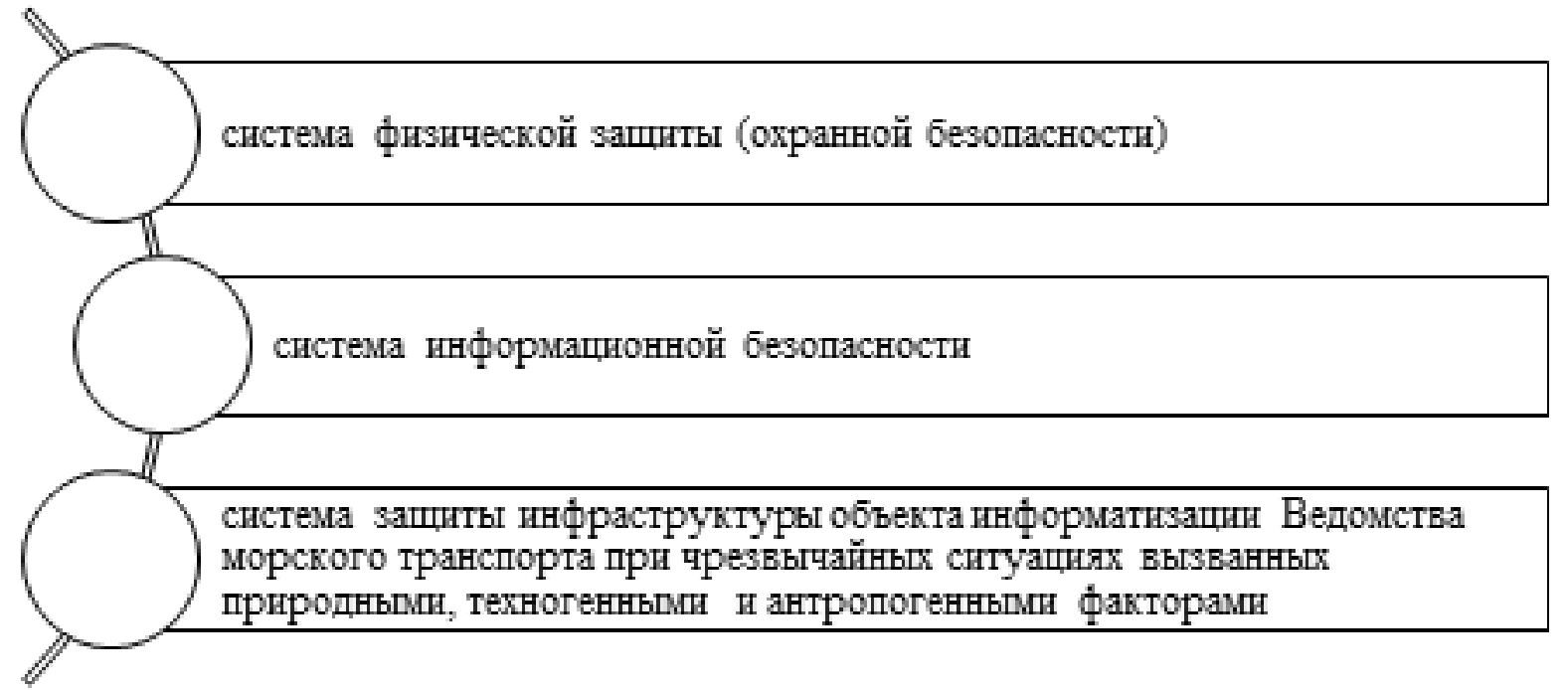

Рис. 2. Обязательные для надежного функционирования подсистемы на морском транспорте

в единой системе мер экономического, политического, организационного и иного характера и должны быть адекватны угрозам жизненно важных интересов общества, личности и государства.

Исходя из этого, безопасность связи - это совокупность связанных друг с другом компонент, функционально реализующих единую политику безопасности Ведомства морского транспорта и работающих в системе его информационного обеспечения на технической основе общих каналов и сетей связи, алгоритмов управления, программного обеспечения (ПО), баз данных [4].
Для реализации возложенных на систему безопасности задач должны создаваться и надежно функционировать следующие подсистемы безопасности, указанные на рис. 2:

Также на сегодняшний день актуализируется проблема, относящаяся к эффективному функционированию системы безопасности радиосвязи, связанная с обеспечением конфиденциальности и скрытности, как правило, с целью защиты коммерческой тайны. Проблемы информационной безопасности в данном случае - это взаимоувязанные понятия, связанные с безопасностью среды передачи данных, защитой информации абонен- 
тов, передаваемой этой средой и собственно функциональной безопасностью систем связи [5].

Фактически говоря, особенность функционирования современных систем связи в техническом плане напрямую определено с потребностью в организации доверенного переноса информации посредством защищенной разнонаправленной интеграции данных и медиа-потоков, которыми, к примеру, являются: движения внутрикорпоративной информации, информации в сети международного обмена, межведомственного обмена информацией.

Безопасность с точки зрения информационной составляющей каждого из элементов системы мореплавания зависит от состояния самого элемента, а также от воздействия на него со стороны иных элементов системы. Учитывая существенные различия между элементами системы, а также наличие разных точек зрения пассажира, судовладельца, исследователя, грузовладельца, эколога и других., в понятие безопасности элемента морской системы может вкладываться различный смысл [6].
Сами проблемы из сегмента радиосвязи напрямую связаны с обменом информации, исходя из этого, одной из ключевых составляющих системы информационной безопасности является современное обеспечение помехозащищенности, надежности радиосвязи, что позволит выработать дополнительный критерий оценки безопасности информационной радиосвязи на море.

Таким образом, основной целью данной работы являлось изучение актуальных вопросов, касающихся обеспечения информационной безопасности радиосвязи на море. В результате работы изучены основные задачи радиосвязи на море, обязательные для надежного функционирования подсистемы на морском транспорте и иные актуальные вопросы, касающиеся темы исследования. Заканчивая данную работу, необходимо отметить, что учет влияния среды распространения радиоволн, кодирования и формирования сигналов помогают оценить уровень информационной безопасности радиосвязи посредством стандартных понятий, к примеру, отношение сигнал-шум, количество ошибок на единицу передаваемой информации и другие.

\section{ЛИТЕРАТУРА}

1. Федеральный закон от 26.07.2017 № 187-Ф3 «0 безопасности критической информационной инфраструктуры Российской Федерации».

2. Зворыкина Ю.В., Глущенко В.В. Обеспечение информационной безопасности на транспорте // Транспорт Российской Федерации. Журнал о науке, практике, экономике. 2016.

3. Gatchin Y.A., Teploukhova 0.A. algorithm of authentication of participants of information interaction at remote loading of the operating system on the thin client // Scientific and technical Bulletin of information technologies, mechanics and optics. 2016.

4. Семенов С.А. Кибербезопасность морского и речного транспорта // Транспорт Российской Федерации. Журнал о науке, практике, экономике. 2018.

5. Andryushechkin Yu.N., Dmitriev V.I. Integrated ship management system / / water transport Safety: Tr. of the International scientific and practical conference.SPb.: SPGUVK, 2003.

6. Sklyar B. Digital communication. Theoretical foundations and practical application-M.: Williams, 2007.

7. Rabinovich A.S. method of user authentication using the TSM service as a trusted element of the NFC system // History and archives. 2015. 